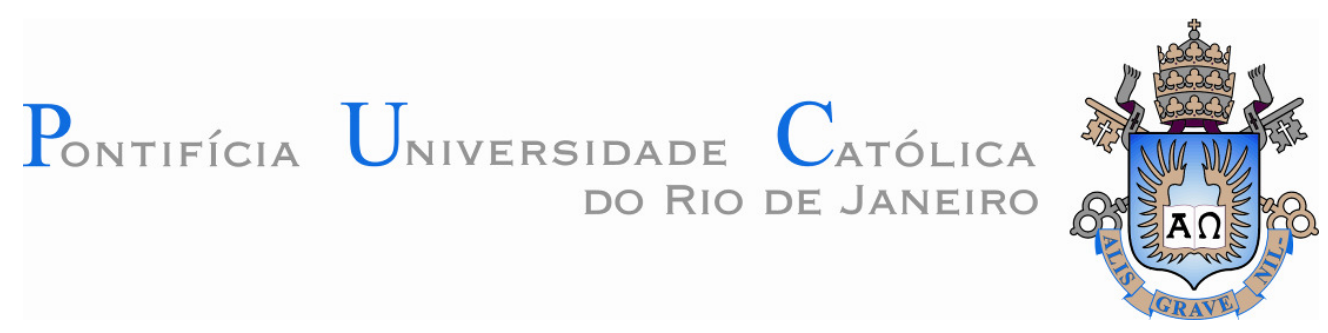

Rafael Richie Lopez Chavez

\title{
Ensaios em Célula Cúbica de Grandes Dimensões para Estudo de Medidas de Contenção de Sólidos em Poços \\ de Petróleo
}

Dissertação de Mestrado

Dissertação apresentada como requisito parcial para obtenção do título de Mestre pelo Programa de PósGraduação em Engenharia Civil do Departamento de Engenharia Civil da PUC-Rio.

Orientadores: Prof. Eurípedes do Amaral Vargas Jr. Co-orientador: Dr. Mauro Bloch 


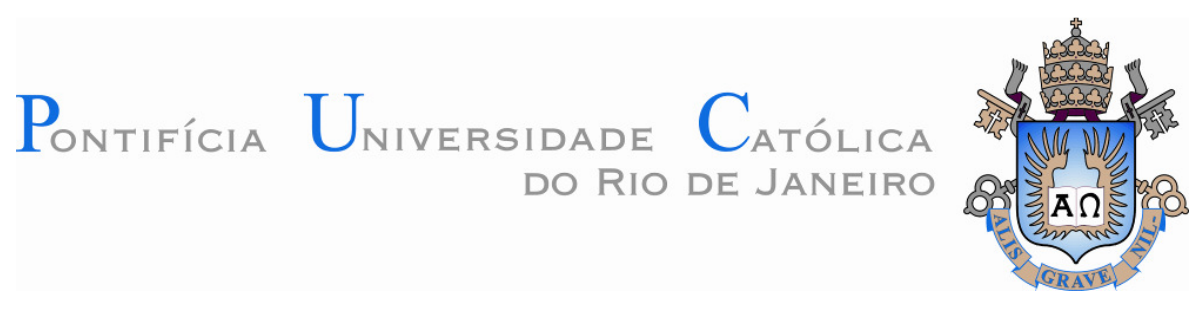

Rafael Richie Lopez Chavez

\section{Ensaios em Célula Cúbica de Grandes Dimensões para Estudo de Medidas de Contenção de Sólidos em Poços de Petróleo}

Dissertação apresentada como requisito parcial para obtenção do título de Mestre pelo Programa de PósGraduação em Engenharia Civil da PUC-Rio. Aprovada pela Comissão Examinadora abaixo assinada.

Prof. Eurípedes do Amaral Vargas Jr. Orientador Departamento de Engenharia Civil - PUC-Rio

Dr. Mauro Bloch

Co-orientador CENPES/Petrobrás

Prof $^{\mathrm{a}}$. Michéle Dal Toé Casagrande Departamento de Engenharia Civil - PUC-Rio

Dra. Raquel Velhoso Departamento de Engenharia Civil - PUC-Rio

Prof. José Eugenio Leal Coordenador Setorial do Centro

Técnico Científico - PUC-Rio 
Todos os direitos reservados. É proibida a reprodução total ou parcial do trabalho sem autorização da universidade, do autor e do orientador.

\section{Rafael Richie Lopez Chavez}

Graduou-se em Engenharia Geológica pela Universidad Nacional de San Agustín de Arequipa - Peru, em 2005. Ingressou no mestrado na Pontifícia Universidade Católica do Rio de Janeiro em 2008, desenvolvendo dissertação na linha de pesquisa de Mecânica das Rochas.

Ficha Catalográfica

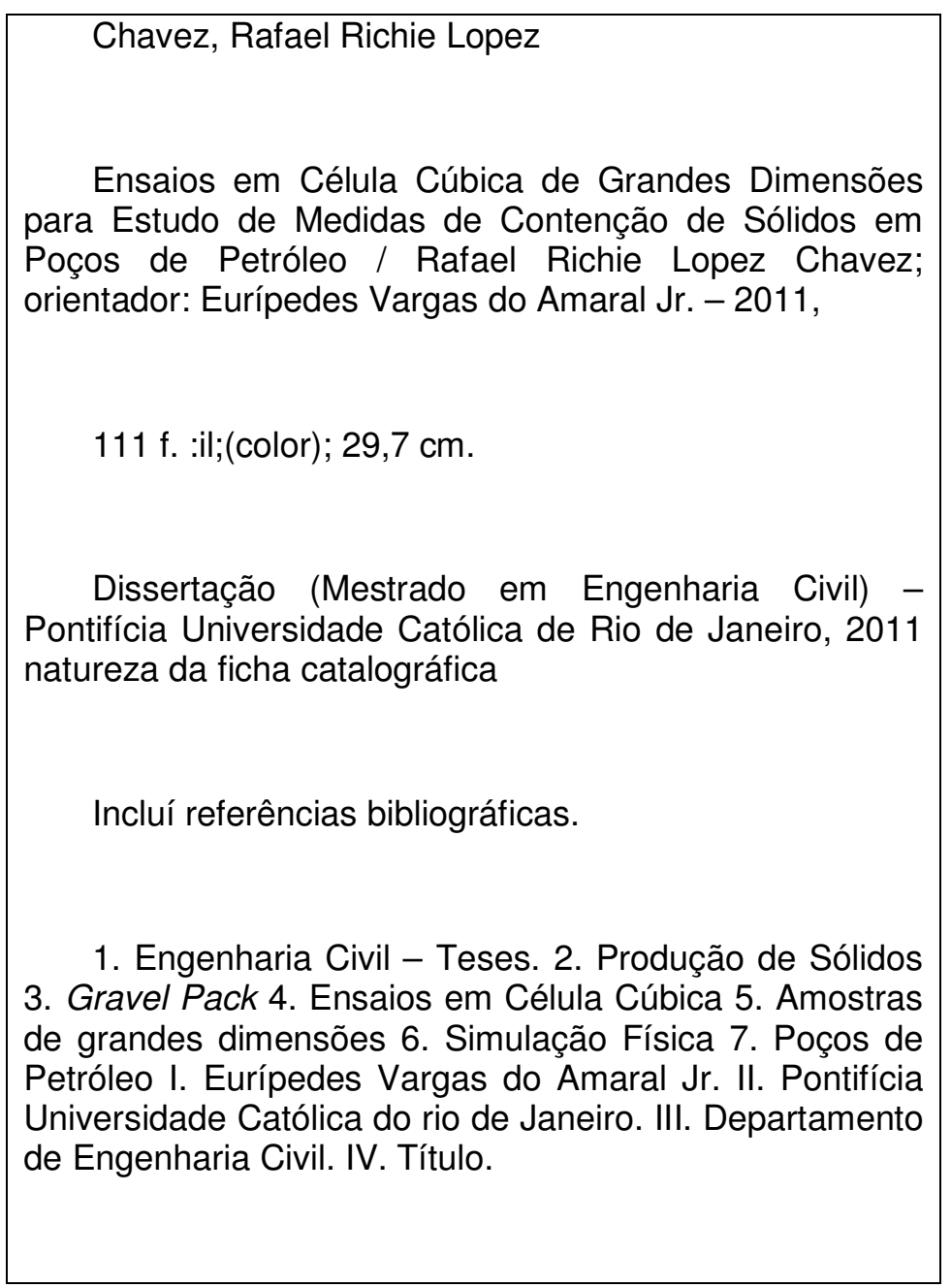

CDD: 624 
Aos meus pais America e Daniel, A minha família. 


\section{Agradecimentos}

A Deus, por sempre iluminar meu caminho.

Ao professor Eurípedes Vargas pela oportunidade de desenvolvimento deste trabalho, pela orientação e confiança depositada desde o começo da dissertação.

Ao meu co-orientador, Mauro Bloch, pela orientação, paciência e sugestões ao longo deste trabalho.

Ao pessoal do Laboratório de Simulação Física do CENPES/PETROBRAS, Windson pela constante ajuda, a Luis pelas dicas, a Lincoln pelas conversas técnicas, Silvio, William, Besa, ao pessoal do laboratório de Mecânica das Rochas, Marcos Dantas, Marcos Soares, Rodrigo, Aline.

Ao pessoal do Laboratório de Estruturas da PUC-Rio, Euclides pelo suporte com as instrumentações, Evandro, Jose, sempre dispostos para ajudar.

Ao pessoal do Laboratório de Estruturas da COPPE/UFRJ, Professor Romildo por permitir o uso das instalações do laboratório, Dra Reila, senhor Julio pelos conselhos e amizade, Alex, Adailton, Flavio, Clodoaldo, e ao Eduardo, que contribuíram neste trabalho.

A empresa BJ Services, pelo fornecimento do Gravel Pack. 
Aos professores do Departamento de Engenharia Civil da PUC-Rio pelos ensinamentos e constante disposição para esclarecer as muitas duvidas.

Aos meus colegas de pós-graduação, pelos bons momentos, discussões e luzes.

A minha colega Flavia pelas dicas, paciência e pela disposição do seu tempo para minhas consultas.

A Rita pela eficiência profissional, apoio e paciência com o pessoal da pósgraduação.

A CNPq pelo apoio financeiro.

A meus pais e irmãos por sempre confiar em mim. 


\section{Resumo}

Chavez, Rafael Richie Lopez; Vargas Jr., Eurípedes do Amaral (Orientador). Ensaios em Célula Cúbica de Grandes Dimensões para Estudo de Medidas de Contenção de Sólidos em Poços de Petróleo. Rio de Janeiro, 2011. 111p. Dissertação de Mestrado - Departamento de Engenharia Civil, Pontifícia Universidade Católica do Rio de Janeiro.

Um dos maiores problemas na indústria do petróleo durante a extração de hidrocarbonetos é a produção de sólidos, grãos de areia que usualmente são gerados a partir de formações pouco consolidadas, como nos arenitos, podendo causar erosão nas linhas de produção, equipamentos de elevação e de superfície, colapso de revestimentos e obstrução do poço. Esses eventos e outros relacionados representam para essa atividade, elevados custos ambientais e econômicos. Nesta dissertação foi simulado experimentalmente o funcionamento de sistemas de contenção de sólidos mais utilizados para poços horizontais sem revestimento, estes ensaios foram executados em blocos de arenitos sintéticos de grandes dimensões, através de uma célula cúbica que permitiu a aplicação de cargas de forma independente em três dimensões, sendo submetidos os corpos de prova a um estado plano de deformações, priorizando-se $\mathrm{n}$ os seguintes objetivos: primeiro analisar o comportamento mecânico de sistemas de contenção de areia em três casos, e segundo observar os efeitos físicos produzidos no gravel pack, quando submetido a um estado anisotrópico de tensões em uma formação com potencial de produção de sólidos. Os resultados foram satisfatórios mostrando em cada caso comportamentos similares, verificando-se que a tela centralizada com o gravel pack oferece melhores condições de suporte para a formação e para estabilidade do poço.

\section{Palavras-chave}

Gravel Pack; Simulação Física; Amostras de Grandes Dimensões; Produção de Sólidos. 


\section{Abstract}

Chavez, Rafael Richie Lopez; Vargas Jr., Eurípedes do Amaral (Advisor). Tests on a Large Cubic Cell for the Study of Solids Containment in Oil Wells. Rio de Janeiro, 2011. 111p. MSc. Dissertation - Departamento de Engenharia Civil, Pontifícia Universidade Católica do Rio de Janeiro.

A major problem in the oil industry during the extraction of hydrocarbons is the production of solid sand grains that are usually generated from some consolidated formations, as in sandstones, may cause erosion on production lines, lifting equipment and surface coatings collapse and obstruction of the well. These and other related events account for this activity, high environmental and economic costs. In this dissertation was simulated experimentally the operation of solid containment systems used to more horizontal wells without coating, these tests were run on synthetic sandstone blocks of large dimensions, through a cubic cell which allowed the application of loads independently in three dimensions, and subjected the specimens to a state plan deformations, focusing on the following objectives: first to analyze the mechanical behavior of systems containing sand in three cases, and second to observe the physical effects produced in the gravel pack, when subjected to an anisotropic state of stresses in a formation with a production potential of solids. The results were satisfactory in each case showing similar behavior, verifying that the central screen with gravel pack offers better support for the formation and stability of the well.

\section{Keywords}

Gravel Pack; Physical Simulation; Large Scale Test; Solids Production. 


\section{Sumário}

Lista de Símbolos

Lista de Abreviaturas

1 Introdução 20

1.1. Relevância da Pesquisa e Objetivos 21

1.2. Organização do Trabalho 21

2 Produção de Sólidos e Sistemas de Contenção 22

2.1. Considerações iniciais 22

2.2. Produção de Sólidos 23

2.2.1. Problemas Relacionados à Produção de Sólidos 23

2.2.2. Mecanismos de Produção de Sólidos 25

2.2.2.1 Ruptura por Cisalhamento 25

2.2.2.2 Ruptura por Tração 25

2.3. Métodos de Controle de Sólidos 26

2.3.1. Métodos Mecânicos $\quad 27$

2.3.1.1. Tubos Ranhurados 27

2.3.1.2. Tubos Telados 28

2.3.1.3. Gravel Pack 31

2.4. Completação de Poços 32

2.4.1 Completação Gravel Packing 32

2.4.2 Completaçaõ Frac Pack 33

2.4.3 Completação Stand Alone 34

3 Fundamentos Teóricos $\quad 35$

3.1. Introdução 35

3.2. Ensaios de Laboratório 36

3.3. Modos de Ruptura $\quad 37$

3.4. Modos de Ruptura induzidos $\quad 39$ 
5 Procedimento Experimental 44

5.1. Introdução 44

5.2. Célula Cúbica 44

5.2.1. Sistema de Válvulas $\quad 47$

5.3. Confecção dos Corpos de Prova 49

5.4. Especificações e Instrumentação dos Tubos 51

5.4.1. Propriedades Químicas e Mecânicas 51

5.4.2. Medição das Deformações Circunferênciais 51

5.4.3. Medição de Deslocamentos Radiais 53

5.4.3.1. Construção do Transdutor de Deslocamentos 53

5.5. Outras especificações $\quad 57$

5.5.1. Interface atuador-cubo $\quad 57$

5.5.2. Lubrificante $\quad 57$

5.5.3. Propriedades do agente de contenção 58

5.6. Casos Estudados 58

5.7. Preparação do Ensaio 60

5.8. Execução do Ensaio 61

5.8.1.Breakout com aplicação de carga no eixo "Y" até os 600 psi 61

5.8.2.Breakout com aplicação de carga no eixo "Y" até os 1000 psi. 63

5.8.3.Tela Centralizada com gravel pack 66

5.8.4.Tela Encostada com gravel pack $\quad 70$

$\begin{array}{ll}\text { 5.8.5.Stand Alone } & 73\end{array}$

6 . Apresentação e Análise dos Resultados 78

6.1. Considerações Iniciais 78

6.2. Resultados obtidos 78

6.2.1. Breakout com aplicação de carga no eixo "Y" até os 600 psi 78

6.2.2. Breakout com aplicação de carga no eixo "Y" até os 1000 psi 79

6.2.3. Tela Centralizada com gravel pack 80

6.2.4. Tela Encostada com gravel pack 86

$\begin{array}{ll}\text { 6.2.5. Stand Alone } & 91\end{array}$ 
7 Conclusões e Sugestões para Trabalhos Futuros 98

7.1. Conclusões 98

7.2. Sugestões para Trabalhos Futuros 99

$\begin{array}{ll}\text { Referências bibliográficas } & 100\end{array}$

Apêndice A. Tabelas de tensão vs deslocamento e tensão vs deformação.

106 


\section{Lista de figuras}

Figura 2.1 - Esquema do transporte dos sólidos (Mendoza, 2003).

Figura 2.2 - Efeitos de erosão de choke, decorrentes da produção de sólidos (Da

Silva, 2008). 24

Figura 2.3 - Diagrama de estabilidade para uma cavidade Morita (1989). 26

Figura 2.4 - Disposição de ranhuras no tubo (Borges, 2007) 28

Figura 2.5 - Tubo Telado Wire-wrapped 28

Figura 2.6 - Tubo Telado Premium. 29

Figura 2.7 - Tubo Telado Pré-empacotado. 30

Figura 2.8 - Detalhes de seções do Tubo Telado Pré-empacotado. 30

Figura 2.9 - Telado Expansível. 31

Figura 2.10 - Gravel Pack em poço revestido. 31

Figura 2.11 - Instalação do Gravel Pack do espaço anular. 32

Figura 3.1 - Tipos de ensaio (GMI, 2006). 36

Figura 3.2 - Representação esquemática das rupturas frágeis a dúcteis (adaptado

Griggs e Handin, 1960). 38

Figura 3.3 - Modo de ruptura Breakout. 39

Figura 3.4 - Tipos de ruptura (a) frágil, (b) dúctil (Papamichos, 2008). 39

Figura 4.1 - Detalhes do esquema do sistema de ensaio poliaxial (Haimson e

Chang, 2000). 41

Figura 4.2 - Equipamento utilizado por Haimson (2007). 42

Figura 4.3 - Célula cúbica para ensaios de estabilidade (Morita at el. 2002) 43

Figura 4.4 - Célula Cúbica do CENPES/PETROBRAS. 43

Figura 5.1 - Detalhes da célula cúbica (Bloch, 2003). 46

Figura 5.2 - Válvulas para acionamento da Célula Cúbica. 47

Figura 5.3 - Esquema do funcionamento das válvulas (Bloch, 2003). 48

Figura 5.4 - Válvulas da bomba secundária. $\quad 48$

Figura 5.5 - Direções de aplicação de cargas no bloco e posição do furo. 49

Figura 5.6 - Corpos de prova sintéticos com as respectivas formas. $\quad 50$

Figura 5.7 - Strain gage colados na superfície interna do tubo. 52

Figura $5.9-1^{\circ}$ transdutor de deslocamento e dispositivo de calibração. $\quad 54$

Figura 5.10 - Transdutor de deslocamentos. 
Figura 5.11 (a) - Curva e constante da calibração do clip gages 1. 55

Figura 5.11 (b) - Curva e constante da calibração do clip-gages 2.

Figura 5.12 - Câmara filmadora Borescope, transdutor e tubos instrumentados. 56

Figura 5.14 - Cerâmica comercial Carbolite, malha 16/20. 58

Figura 5.15 - Retenção do gravel pack nos extremos nos furos do bloco. $\quad 60$

Figura 5.16 - Transdutor de deslocamento no interior do tubo instrumentado. 61

Figura 5.17 - Vista das direções de aplicação de cargas no bloco. 62

Figura 5.18 - Câmara filmadora e led de iluminação instalada na placa do atuador.

Figura 5.19 - Bloco fraturado depois de encostar os atuadores. 64

Figura 5.20 - Tubo centralizado com o gravel pack 16/20. 67

Figura 5.21 - Tampa utilizada para manter o gravel pack. 68

Figura 5.23 - Tubo encostado com o gravel pack. 71

(a) - Instalação do tubo instrumentado e o tradutor de deslocamento. 72

Figura 5.24 (b) - Preenchimento com o gravel pack. 73

Figura 5.25 - Bloco com o sistema de contenção instrumentado. 74

(a) - Passagem de câmara filmadora através de um conduto de $13 \mathrm{~mm}$ de diâmetro

Figura 5.26 (b) - Instalação da câmara filmadora dentro do bloco. 76

Figura 6.1 - "Caso Breakout com aplicação de carga no eixo "Y" até os 600psi", no minuto 22’00.

Figura 6.2 - "Caso Breakout com aplicação de carga no eixo "Y" até os 1000psi", no minuto 19'00. 79

Figura 6.3 - Curvas dos deslocamentos no eixo Z e Y. 81

Figura 6.4 - Curvas dos deslocamentos no eixo "Z" e "Y".

(a) - Fratura interna do bloco. $\quad 82$

Figura 6.5 (b) - Fraturas no bloco A-1b. 83

Figura 6.6 - Esmagamento do tubo pelo fraturamento. 83

Figura 6.7 - Curva Tensão VS Deslocamento. 84

Figura 6.8 - Curva Tensão vs Deslocamento. 84

Figura 6.9 - Curva Tensão vs Deformação. 85

Figura 6.10 - Deformação do tubo pelas cargas aplicadas, segundo as curvas obtidas. $\quad 86$

Figura 6.11 - Fraturamento do bloco B-1. 87 
Figura 6.12 - Curva Tensão vs Deslocamento. $\quad 87$

Figura 6.13 - Grãos de gravel pack mobilizados embaixo do tubo. 88

Figura 6.14 - Fraturamento do bloco B-2. 88

Figura 6.15 - Tensão vs Deslocamento. 89

Figura 6.16 - Tensão vs Deslocamento. $\quad 89$

Figura 6.17 - Tensão vs Deformação. $\quad 90$

Figura 6.18 - Bloco sem fraturas no final do ensaio. 91

Figura 6.19 - Interior do furo fraturado do bloco C-1. 91

Figura 6.20 - Tensão vs Deslocamento do bloco C-2. 92

Figura 6.21 - Tensão vs Deformação do Strain-lateral no bloco C-2. 93

Figura 6.22 - Tubo ovalizado pelos sólidos produzidos. 93

Figura 6.23 - Formato (Breakout) depois dos carregamentos. 94

Figura 6.24 - Bloco C-2 depois dos carregamentos. 94

Figura 6.25 - Sólidos produzidos no interior do furo. 95

Figura 6.26 - Curvas de tensão vs deformação do bloco C-3 95

Figura (a) - Bloco C-3 no final do ensaio. 96

Figura 6.27(b) - Bloco C-3 retirado da Câmara Cúbica. 96

Figura 6.28 - Tubo pressionado no bloco. 97 


\section{Lista de tabelas}

Tabela 5.1 - Propriedades do arenito sintético $\quad 50$

Tabela 5.2 - Propriedades do tubo de latão (Villarroel, 2009). 51

Tabela 5.3 - Seqüência de carregamentos aplicados no bloco. 63

Tabela 5.4 - Seqüência da aplicação de carregamentos no bloco. 65

Tabela 5.5 - Seqüência da aplicação de carregamentos no bloco. 66

Tabela 5.6 - Seqüência da aplicação de carregamentos no bloco. 67

Tabela 5.7 - Nova seqüência dos carregamentos aplicados no bloco. 68

Tabela 5.8 - Seqüência da aplicação de carregamentos no bloco . 69

Figura 5.22 - Seção transversal do tubo com o posicionamento dos strain gage 70

Tabela 5.9 - Seqüência da aplicação de carregamentos no bloco. 70

Tabela 5.10 - Seqüência dos carregamentos aplicados no bloco. 71

Tabela 5.11 - Seqüência dos carregamentos aplicados no bloco. 72

Tabela 5.12 - Seqüência dos carregamentos aplicados no topo. 73

Tabela 5.14 - Seqüência dos carregamentos aplicados no bloco. 77 


\section{Lista de quadros}

Quadro 5.1 - Definição das linhas hidráulicas de acionamento da Célula Cúbica

(Bloch, 2003). 


\section{Lista de Símbolos}

\section{Romanos}

$\begin{array}{ll}C & \text { Coesão } \\ E & \text { Módulo de elasticidade } \\ P & \text { Pressão } \\ X & \text { Eixo principal menor } \\ Y & \text { Eixo principal intermediário } \\ Z & \text { Eixo principal maior }\end{array}$




\section{Gregos}

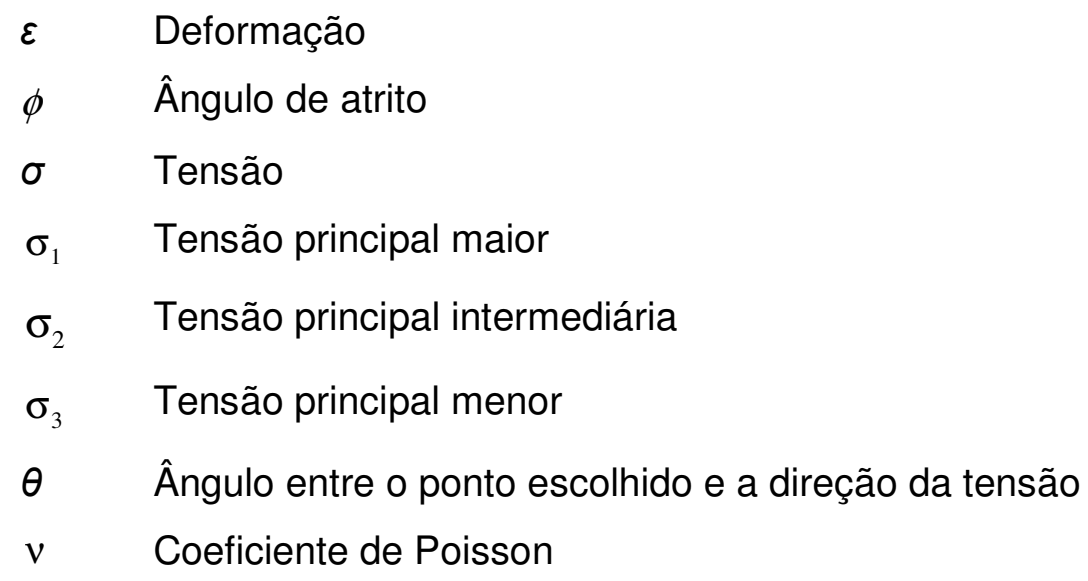




\section{Lista de Abreviaturas}

CP $\quad$ Corpo de prova

CPs Corpos de prova

TEP Gerência de Tecnologia e Engenharia de Poços

RGO Razão Gás Óleo

RAO Razão Água Óleo 